\title{
GAMBARAN PENGGUNAAN OBAT PADA PASIEN APPENDICITIS TERHADAP KESEHATAN USUS DI RUMAH SAKIT ANNISA CIKARANG
}

\author{
Sri Rahayu ${ }^{1 *}$, Kiki Loviana ${ }^{2}$, Rida Emelia ${ }^{3}$ \\ Politeknik Piksi Ganesha, Bandung, Indonesia ${ }^{1,2,3}$ \\ srirahayu1251@gmail.com ${ }^{1 *}$, kikiloviana@gmail.com ${ }^{2}$, emeliarida1310@gmail.com ${ }^{3}$
}

Received: 03-08-2021

Revised : 11-09-2021

Accepted: 24-09-2021

\begin{abstract}
Abstrak
Latar Belakang: Appendicitis merupakan radang pada appendiks dan lebih dikenal dengan radang usus buntu yang dapat menyerang semua umur baik laki-laki ataupun perempuan sehingga menyebabkan nyeri abdomen yang dapat mengganggu aktifitas sehari-hari dan salah satu tindakan yang harus ditempuh adalah dengan appendiktomi. Tujuan: Penelitian ini bertujuan untuk mengetahui obat anestesi apa saja yang digunakan serta obat-obat yang digunakan sebelum, sedang dan setelah operasi jugaobat yang dibawa pulang pada saat pulang rawat inap.
\end{abstract}

Metode: Metode penelitian yang digunakan adalah penelitian deskriptif dengan survey cross sectional yang dikumpulkan pada tahun 2020 dari seluruh populasi (415 orang) dan sampel (80 orang) dengan menggunakan data rekam medik. Penentuan sampel dengan menggunakan rumus Slovin.

Hasil: Hasil penelitian menunjukkan usia terbanyak yang mengalami appendicitis adalah 14-22 tahun sebanyak 32.5\% (26 orang) dan terjadi pada perempuan sebanyak $71,25 \%$ (57 orang) dengan diagnosa appendicitis akut sebanyak 62,5\% (50 orang) serta menggunakan anestesi lokal 90\% (72 orang) dan dirawat selama 4 hari sebanyak 50\% (40 orang). Pola terapi yang digunakan sebelum operasi adalah kombinasi Cairan RL + Ceftriaxone inj sebanyak 55\% (44 orang), pada saat operasi kombinasi Cairan RL + Bunascan inj + Ondansetron $8 \mathrm{mg}$ inj + Ranitidine inj + Tramadol inj sebanyak $43,75 \%$ (35 orang), setelah operasi kombinasi Cairan RL +Ceftriaxon inj + Ketorolac inj + Ranitidin inj sebanyak 23,75\% (19 orang) dan kombinasi Cairan RL + Ceftriaxon inj + Ranitidin inj + Tofedex inj sebanyak 23,75\% (19 orang), obat yang dibawa pulang rawat kombinasi Asam Mefenamat $500 \mathrm{mg}$ tab + Cefixime $200 \mathrm{mg}$ tab + Ranitidin tab sebanyak $27,5 \%$ (22 orang).

Kesimpulan: Usia pasien terbanyak yang mengalami appendisitis di Rumah Sakit Annisa Cikarang yaitu pada usia 14 - 22 tahun sebanyak 32,5\%(26 orang) dan terjadi pada pada perempuan sebanyak $71,25 \%$ (57 orang.

Kata kunci: appendicitis; usia pasien; obat appendicitis. 


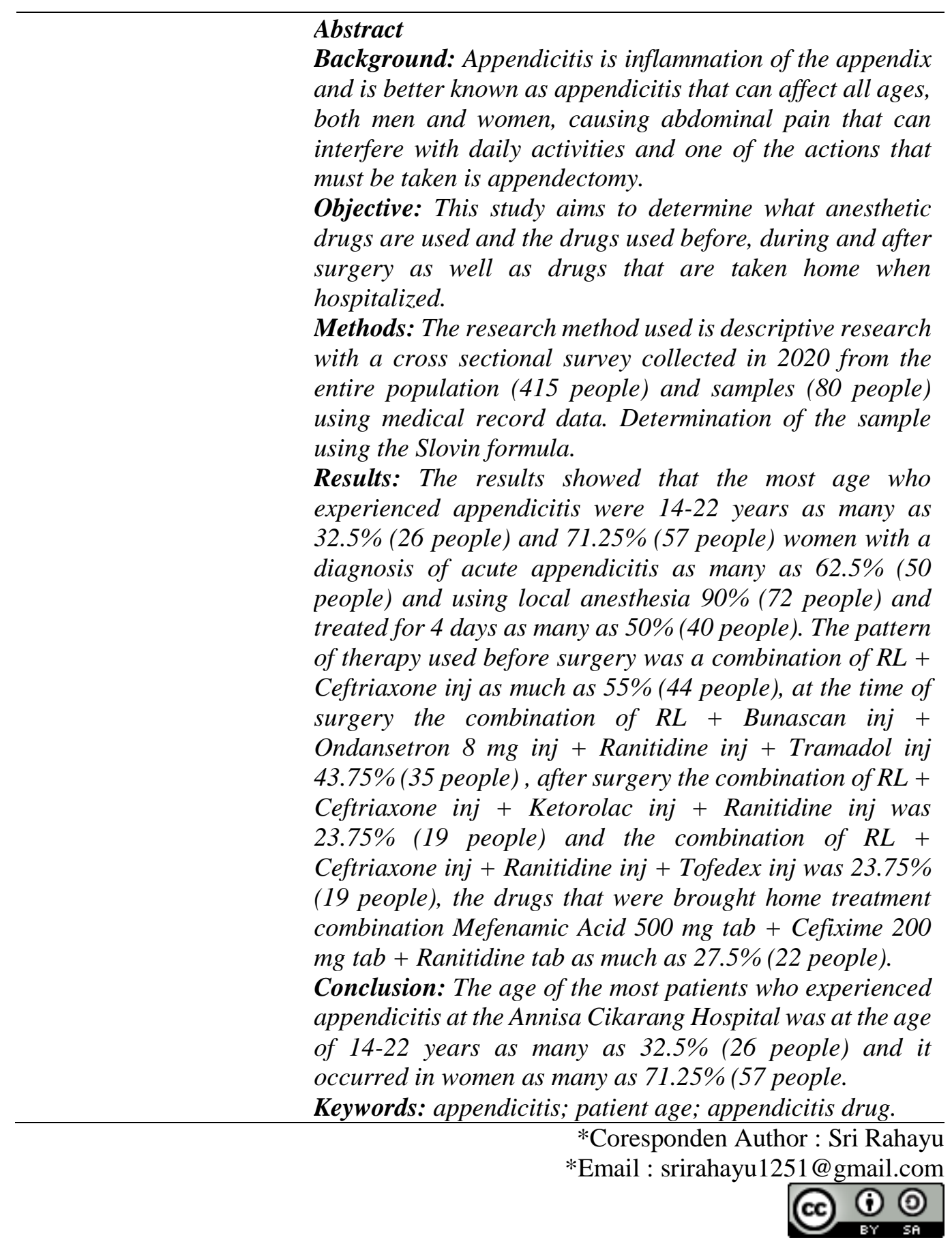

\section{PENDAHULUAN}

Apendisitis merupakan masalah kesehatan yang sering terjadi di Indonesia. Apendisitis memerlukan tindakan bedah, karena termasuk dalam peradangan akut. Berdasarkan hasil Survey Kesehatan Rumah Tangga (SKRT) di Indonesia, insiden apendisitis di Indonesia menempati urutan tertinggi di antara kasus kegawatan abdomen lainnya (Depkes, 2009). Appendicitis adalah peradangan pada appendiks atau pada umumnya lebih dikenal dengan radang usus buntu. Appendicitis dapat menyerang baiklakilaki ataupun perempuan pada semua umur yang dapat menyebabkan nyeri abdomen. Faktor penyebab peradangan ini karena predeposisi yaitu hiperflasia dari folikel limfoid,adanya 
fekolit dalam lumen appendiks atau adanya benda asing seperti cacing dan biji-bijian (Awaluddin, 2020).

Penyakit radang usus buntu disebabkan oleh bakteri dan makan cabai bersama bijinya atau jambu klutuk beserta bijinya sering kali tidak tercerna dalam tinja dan menyelinap kesaluran appendiks sebagai benda asing. gejala radang usus buntu umumnya mengalami sakit perut, terutama dimulai di sekitar pusar dan bergerak kesamping kanan bawah, penurunan nafsu makan, mual dan muntah, serta diare (Wiyandra \& Yenila, 2018).

Apendiktomi harus segera dilakukan apabila penderita mengalami serangan apendisitis akut (Bachur et al., 2012). Apendiksitis bila tidak ditangani secara cepat, maka akan menimbulkan komplikasi, komplikasi tersering yang dialami pasien apendiksitis akut adalah apendiksitis perforasi dengan pasien apendiksitis perforasi tanpa peritonitis umum 23 orang $(39,7 \%)$, sedangkan yang telah mengalami peritonitis umum sebanyak 14 orang $(24,1 \%)$ (Shiddiq, 2013).

Menurut World Health Organization (WHO) tahun 2014 menunjukkan 7\% penduduk di Negara Barat menderita apendisitis dan terdapat lebih dari 200.000 apendiktomi dilakukan di Amerika Serikat setiap tahunnya. Badan World Health Organization (WHO) menyebutkan insidens apendisitis di Asia dan Afrika pada tahun 2014 adalah 4,8\% dan 2,6\% penduduk dari total populasi (Organization, 2014). Di Indonesia insiden apendisitis cukup tinggi, terlihat dengan adanya peningkatan jumlah pasien dari tahun ke tahun. Berdasarkan data yang diperoleh dari Depkes RI tahun 2016, kasus apendisitis pada tahun 2016 sebanyak 65.755 orang dan pada tahun 2017 jumlah pasien apendisitis sebanyak 75.601 orang (Depkes, 2016). Dinkes Jawa Timur menyebutkan pada tahun 2017 jumlah kasus apendisitis di Jawa Timur sebanyak 5.980 penderita dan 177 penderita diantaranya menyebabkan kematian (Nurlina et al., 2019).

Pada tahun 2009 dan 2010 appendicitis merupakan penyakit tidak menular tertinggi kedua di Indonesia terhadap pasien rawat inap. Informasi data yang diperoleh dari Kementerian Kesehatan RI tahun 2009 kejadian appendicitis di Indonesia sebesar 596.132 orang dengan persentase 3,36\% dan meningkat pada tahun 2010 menjadi 621.435 orang dengan persentase 3,53\% (Iㅡ, 2008).Nyeri yang ditimbulkan oleh appendicitis dapat mengganggu aktifitas sehari-hari. Salah satu tindakan yang harus ditempuh untuk menghilangkan nyeri secara permanen yaitu dengan cara appendiktomi. Appendiktomi merupakan pengobatan melalui prosedur tindakan operasi untuk mengangkat usus buntu yang yang terinfeksi. Appendiktomi dilakukan sesegera mungkin untuk menurunkan resiko perforasi lebih lanjut seperti peritonitis atau abses (Waisani \& Khoiriyah, 2020).

Nyeri yang terkontrol sangat perlu dilakukan setelah operasi karena dapat mengurangi kecemasan, dapat bernafas lebih lega, dan dapat mentoleransi mobilisasi dengan cepat. Selain penanganan secara farmakologi, teknik non farmakologi juga dapat digunakan dalam pengelolaan nyeri yaitu dengan melakukan teknik relaksasi, yang merupakan tindakan eksternal yang dapat mempengaruhi respon internal individu terhadap nyeri. Penanganan nyeri melalui teknik relaksasi yaitu meliputi nafas dalam, masase, relaksasi otot, meditasi dan perilaku (Wulandari, 2021).

Berdasarkan uraian di atas, peneliti tertarik untuk melakukan penelitian tentang gambaran penggunaan obat pada pasien appendicitis di Rumah Sakit Annisa Cikarang mulai saat pasien masuk, selama operasi, setelah operasi dan sampai pasien pulang dari ruangan rawat inap.

\section{METODE PENELITIAN}

Penelitian ini merupakan penelitian deskriptif dengan survei cross sectional yang merupakan jenis metode penelitian observasi yang bersifat menganalisis serangkaian data 
variabel penelitian yang telah dikumpulkan pada tahun 2020 dari seluruh jenis populasi dan sampel dengan menggunakan data rekam medik (medical record) pasien Rumah Sakit Annisa Cikarang yang telah menjalani operasi appendiktomi (Soendari, 2012). Penelitian ini menggunakan rumus slovin untuk mengetahui jumlah sampel pasien appendiktomi (Setiawan, 2007). Populasi sampel dalam penelitian ini sebanyak 80 orang sampel mengunakan pola terapi penggunaancairan $\mathrm{RL}+$ Ceftriaxon inj.

\section{HASIL DAN PEMBAHASAN}

\section{A. Hasil Penelitian}

1. Distribusi pasien appendisitis berdasarkan usia

Hasil penelitian yang dilakukan di Rumah Sakit Annisa Cikarang, pada Januari Desember 2020 dengan sampel data Rekam Medik sebanyak 80 orang dapat dilihat dari tabel sebagai berikut :

Tabel 1. Distribusi usia pasien appendicitis

\begin{tabular}{lcc}
\hline Usia & n & \% \\
\hline $5-13$ tahun & 2 & 2,5 \\
\hline $14-22$ tahun & 26 & 32,5 \\
\hline $23-31$ tahun & 13 & 16,25 \\
\hline $32-40$ tahun & 17 & 21,25 \\
\hline $41-49$ tahun & 6 & 7,5 \\
\hline $50-58$ tahun & 11 & 13,75 \\
\hline $59-67$ tahun & 5 & 6,25 \\
\hline Total & $\mathbf{8 0}$ & $\mathbf{1 0 0}$ \\
\hline
\end{tabular}

Berdasarkan tabel 1, dari hasil penelitian yang ditampilkan dalam tabel di atas dapat disimpulkan bahwa usia yang paling tinggi mengalami appendiktomi adalah pada usia 14 -22 tahun yaitu sebanyak $32,5 \%$ dan yang paling rendah pada usia $5-13$ tahun sebanyak $2,5 \%$.

2. Distribusi jenis kelamin pasien appendicitis

Tabel 2. Distribusi jenis kelamin pasien appendicitis

\begin{tabular}{lcc}
\hline Jenis Kelamin & n & \% \\
\hline Laki - Laki & 23 & 28,75 \\
\hline Perempuan & 57 & 71,25 \\
\hline Total & 80 & 100 \\
\hline
\end{tabular}

Berdasarkan tabel 2, jenis kelamin yang banyak mengalami appendiktomi adalah pada perempuan yaitu 71,25\% (57 orang), sedangkan laki-laki 28.75\% (23 orang).

3. Jenis diagnosa pada pasien appendicitis di Rumah Sakit Annisa Cikarang

Tabel 3. Jenis diagnosa pada pasien appendicitis di Rumah Sakit Annisa Cikarang

\begin{tabular}{llc}
\hline Jenis Diagnosa & n & \% \\
\hline Akut & 50 & 62,5 \\
\hline Kronik & 30 & 37,5 \\
\hline
\end{tabular}


Berdasarkan tabel 3 di atas, hasil dari diagnosa pada pasien appenditicitis di Rumah Sakit Annisa Cikarang dengan jenis diagnosa akut $\mathrm{n}$ sebanyak 50 dan persentasenya 62,5\%, sedangkan dengan jenis diagnosa kronik sebanyak 30 dan 37,5\%. Dapat disimpulkan bahwa pasien dengan diagnosa appenditicitis di Rumah Sakit Annisa Cikarang jenis diagnosa akut lebih banyak dialami pasien.

4. Obat anestesi yang digunakan di Rumah Sakit Annisa Cikarang

Tabel 4. obat anestesi yang digunakan di Rumah Sakit Annisa Cikarang

\begin{tabular}{lcc}
\hline Obat Anestesi & n & \% \\
\hline Bunascan inj (Buvipacain) & 72 & 90 \\
\hline Bunascan inj + Recofol inj & 3 & 3,75 \\
\hline Recofol inj (Propofol) & 5 & 6,25 \\
\hline Total & 80 & 100 \\
\hline
\end{tabular}

Berdasarkan tabel 4 di atas, hasil obat anetesi Bunascan inj (Buvipacain) yang lebih banyak dikonsumsi oleh pasien sebab pasien appenditicitis di Rumah Sakit Annisa Cikarang.

\section{B. Pembahasan}

Pola terapi yang digunakan sebelum, saat dan setelah operasi appendicitis di Rumah Sakit Annisa Cikarang pola terapi yang digunakan sebelum operasi appendicitis di Rumah Sakit Annisa Cikarang 55\% (44 orang) dari 80 orang sampel mengunakan pola terapi penggunaancairan RL + Ceftriaxon inj. Hal ini bertujuan sebagai profilaksis sebagai pencegah infeksi insisi pembedahan (Makani \& Andayani, n.d. 2019).

Pola terapi yang digunakan pada saat operasi appendicitis di RumahSakit Annisa Cikarang yang terbanyak adalah berupa pemberian cairan Cairan RL + Bunascan inj + Ondansetron 8 mg inj + Ranitidin inj + Tramadol inj 43,75\% (35 orang). Pola terapi obat yang digunakan setelah operasi appendicitis terabanyak adalah dengan pola terapi pemeberian cairan RL + Ceftriaxon inj + Ketorolac inj + Ranitidin inj sebanyak 23,75\% (19 orang) dan dengan pola terapi Cairan RL + Ceftriaxon inj + Ranitidin inj + Tofedex inj sebanyak 23.75\% (19 orang).

Berdasarkan penelitian pola terapi obat pulang pada pasien appendicitis di Rumah Sakit Annisa Cikarang pada tahun 2020 adalah dengan pola kombinasi Asam Mefenamat $500 \mathrm{mg}$ tab + Cefixime $200 \mathrm{mg}$ tab + Ranitidin tab sebanyak 27,5\% (22 orang). Dengan pemberian kombinasi analgetik dan antibiotik pada saat pulang bertujuan untuk mengurangi rasa sakit dan mencegah infeksi dan juga memulihkan luka insisi yang dilakukan pada saat pembedahan di ruang operasi.

Pada terapi pengobatan Appendicitis selalu diberikan antibiotik karena Appendicitis merupakan penyakit yang disebabkan infeksi oleh bakteri (Dewi, n.d.). Faktor pencetusnya seperti yang dikemukakan oleh Awaluddin adalah menjadi media bagi bakteri (Escherichia Coli) untuk berkembang biak, maka antibiotik ini digunakan untuk menekan perkembangbiakan bakteri. Selain antibiotik diperlukan juga obat analgetik (penawar nyeri), analgetik sendiri dapat merangsang peningkatan asam lambung maka sebagai profilaksis diberikan Ranitidin tab (golongan $\mathrm{H}_{2}$ blocker). 
Lama rawat inap pada pasien appendicitis di Rumah Sakit Annisa Cikarang pada tahun 2020 berdasarkan penelitian yang terbanyak adalah 50\% (4 hari). Hal ini pada umumnya pasien menunjukkan bahwa kondisi kesehatannya mengalami perbaikan dibandingkan dengan pada saat sebelum operasi, kemudian melanjutkan pemulihan luka di rumah setelah pulang dari rawat inap.

\section{KESIMPULAN}

Usia pasien terbanyak yang mengalami appendisitis di Rumah Sakit Annisa Cikarang yaitu pada usia 14 - 22 tahun sebanyak 32,5\%(26 orang) dan terjadi pada pada perempuan sebanyak 71,25\%(57 orang. Diagnosa yang paling banyak ditegakkan oleh dokter bedah di Rumah Sakit Annisa Cikarang adalah appendisitis akut sebanyak 62,5\%(50 orang). Jenis anestesi yang banyak digunakan pada saat operasi appendicitis di Rumah Sakit Annisa Cikarang adalah anestesi lokal sebanyak 90\% (72 orang).

Pola terapi obat pasien appendicitis sebelum operasi di Rumah Sakit Annisa Cikarang adalah kombinasi cairan RL + Ceftriaxon inj sebanyak 55\%(44 orang). Pola terapi obat pasien appendicitis pada saat operasi di Rumah Sakit Annisa Cikarang adalah kombinasi cairan RL + Bunascan inj + Ondansetron 8 mg inj +Ranitidin inj + Tramadol inj sebanyak $43.75 \%$ (35 orang). Pola terapi obat pasien appendicitis setelah operasi di Rumah Sakit Annisa Cikarang adalah pemeberian cairan RL + Ceftriaxon inj + Ketorolac inj + Ranitidin inj sebanyak 23,75\% (19 orang) dan dengan pola terapi Cairan RL + Ceftriaxon inj + Ranitidin inj + Tofedex inj sebanyak 23.75\% (19 orang). Pola terapi obat pasien appendicitis di Rumah Sakit Annisa Cikarang pada saatpulang adalah kombinasi Asam Mefenamat $500 \mathrm{mg}$ tab + Cefixime $200 \mathrm{mg}$ tab + Ranitidin tab sebanyak 27,5\% (22 orang). Lama rawat inap pasien appendicitis di Rumah Sakit Annisa Cikarang adalah 4 hari sebanyak $50 \%$ (40 orang).

\section{BIBLIOGRAFI}

Awaluddin, A. (2020). Faktor Risiko Terjadinya Apendisitis Pada Penderita Apendisitis Di Rsud Batara Guru Belopa Kabupaten Luwu Tahun 2020. Jurnal Kesehatan Luwu Raya, 7(1), 67-72.

Bachur, R. G., Dayan, P. S., Bajaj, L., Macias, C. G., Mittal, M. K., Stevenson, M. D., Dudley, N. C., Sinclair, K., Bennett, J., \& Monuteaux, M. C. (2012). The effect of abdominal pain duration on the accuracy of diagnostic imaging for pediatric appendicitis. Annals of Emergency Medicine, 60(5), 582-590.

Depkes, R. I. (2009). Profil kesehatan indonesia. Jakarta: Depkes RI, 200.

Depkes, R. I. (2016). Departemen Kesehatan Republik Indonesia. Farmakope Indonesia.

Dewi, A. A. W. T. (n.d.). Evaluasi Penggunaan Antibiotika Profilaksis Pada Pasien Operasi Apendisitis Akut Di Instalasi Rawat Inap Rumah Sakit Baptis Batu Jawa Timur Tahun 2011.

Makani, M., \& Andayani, T. M. (2019). Pengaruh Pemberian Antibiotik Profilaksis Terhadap Infeksi Luka Operasi pada Pasien Bedah Obstetri dan Ginekologi di RSUP Dr. Sardjito. Majalah Farmaseutik, 17(1), 29-37.

Nurlina, I. E., Sulistyowati, A., Putra, K. W. R., \& Annisa, F. (2019). Asuhan keperawatan pada sdr. S dengan diagnosa medis post operasi apendiktomy di ruang dahlia rs brawijaya tk iii surabaya. Akademi Keperawatan Kerta Cendekia Sidoarjo.

Organization, W. H. (2014). WHO guidelines for indoor air quality: household fuel combustion. World Health Organization.

RI, D. (2008). Keputusan Menteri Kesehatan Republik Indoneia Nomor. 129 Tahun 2009 
Tentang Standar Pelayanan Minimal Rumah Sakit. Jakarta: Kemenkes RI.

Setiawan, N. (2007). Penentuan ukuran sampel memakai rumus slovin dan tabel krejciemorgan: telaah konsep dan aplikasinya. Universitas Padjadjaran. Bandung.

Shiddiq, M. (2013). Suhu Tubuh Dan Nilai Granulosit Praoperasi Pasien Apendisitis Akut Berkomplikasi Di Rsud Dokter Soedarso Pontianak Tahun 2012. Jurnal Mahasiswa PSPD FK Universitas Tanjungpura, 2(1).

Soendari, T. (2012). Metode Penelitian Deskriptif. Bandung, UPI. Stuss, Magdalena \& Herdan, Agnieszka, 17.

Waisani, S., \& Khoiriyah, K. (2020). Penurunan Intensitas Skala Nyeri Pasien Appendiks Post Appendiktomi Menggunakan Teknik Relaksasi Benson. Ners Muda, 1(1), 6877.

Wiyandra, Y., \& Yenila, F. (2018). Sistem Pakar Deteksi Apendisicitis. Jurnal KomtekInfo, $5(3), 81-91$.

Wulandari, K. (2021). Gambaran Pengelolaan Nyeri Akut Pada Pasien Post Apendiktomi Di Rsud Sanjiwani Gianyar Tahun 2021. Jurusan Keperawatan 2021.

(C) 2021 by the authors. Submitted for possible open access publication under the

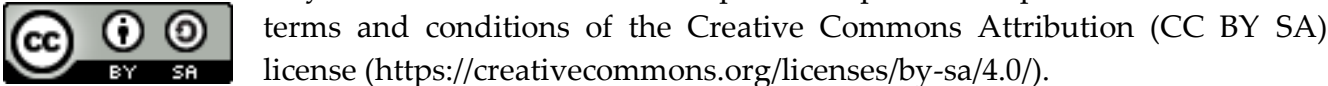

